\title{
LIKUIDITAS, SOLVABILITAS DAN AKTIVITAS BERPENGARUH TERHADAP PROFITABILITAS PADA PERUSAHAAN SUBSEKTOR PERDAGANGAN ECERAN
}

\author{
Lioni Indrayani \\ Fakultas Ekonomi dan Bisnis, Universitas Pamulang \\ Email :dosen02626@unpam.ac.id
}

\begin{abstract}
This study aims to examine the effect of Current Ratio (CR), Debt to Total Asset Ratio (DAR), and Total Asset Turn Over (TATO) to Return On Asset (ROA) of retail trade sub-sector companies. The population in this research is financial statement from retail trade sub-sector companies listed on the Indonesia Stock Exchange period 2012-2018. While the sample of this research was determined by purposive sampling. This research uses E-Views to analyst data panel regression with Fixed Effect Model (FEM). The result of research showed Current Ratio (CR) has no effect on Return on Asset (ROA), Debt to Total Asset Ratio(DAR) and Total Asset Turn Over (TATO) had a significant positive effect on Return on Asset(ROA).
\end{abstract}

Keywords: Current Ratio; Debt to total Asset Ratio; Total Asset Turn Over; Return On Asset

\begin{abstract}
Abstrak
Penelitian ini akan bertujuan menguji pengaruh rasio yang terdiri dari Current Ratio (CR), Debt to total Asset Ratio (DAR), dan Total Asset Turn Over (TATO) terhadap profitabilitas Return On Asset (ROA) perusahaan subsektor perdagangan eceran (retail trade). Populasi dalam penelitian ini adalah laporan keuangan dari perusahaan subsektor perdagangan eceran (retail trade) yang terdaftar di Bursa Efek Indonesia (BEI) periode 2012-2018. Penelitian ini menerapkan kriteria tertentu dalam menentukan sampel yang sering disebut dengan Purposive Sampling. Metode analisis data dalam penelitian ini adalah regresi data panel dan lebih cocok dengan Metode Fixed Effect Model (FEM) yang menggunakan program Eviews sebagai program pengolah data. Hasil penelitian menunjukkan bahwa Current Ratio (CR) tidak memiliki pengaruh terhadap Return on Asset (ROA), Debt to Total Asset Ratio (DAR) dan Total Asset Turn Over (TATO) berpengaruh signifikan terhadap Return on Asset (ROA).
\end{abstract}

Kata kunci: Current Ratio; Debt to total Asset Ratio; Total Asset Turn Over; Return On Asset

\section{PENDAHULUAN}

* Corresponding author's e-mail: dosen02626@unpam.ac.id

http://openjournal.unpam.ac.id/index.php/JABI 
Perusahaan dalam kegiatan bisnisnya umumnya memiliki tujuan untuk mendapatkan keuntungan sebanyak-banyaknya dengan menekan pengeluaran seminimal mungkin. Kasmir (2008, h.8) menjelaskan bahwa memaksimalkan nilai perusahaan adalah memaksimalkan nilai saham agar perusahaan memperoleh kepercayaan dari lembaga keuangan untuk memperoleh pinjaman dengan persyaratan lebih lunak dan kepercayaan dari para supplier, mampu memaksimalkan penghasilan setelah pajak bertujuan mensejahterakan para stakeholder dengan meningkatkan kualitas hidup.

Analisis rasio keuangan sebagai dasar informasi manajer keuangan untuk menyusun perencanaan dan pengendalian keuangan yang bertujuan memperbaiki profitabilitas, menghindari situasi terjaminnya keadaan untuk kas, serta meningkatkan kemampuan perusahaan untuk mencapai efisiensi dan efektivitas.

Melalui analisis rasio keuangan terdapat aspek keuangan antara lain likuiditas, aktivitas, profitabilitas dan solvabilitas atau leverage. Ada tiga jenis rasio profitabilitas yang dominan dipakai dalam penelitian terdahulu mengenai kinerja perusahaan yaitu profit margin, return on assets (ROA), dan return on equity (ROE). Serangkaian kebijakan perusahaan dipengaruhi oleh faktor-faktor lingkungan menyebabkan Return On Assets (ROA) menjadi salah satu indikator terbaik dalam mengukur kinerja perusahaan. ROA mengukur kesanggupan perusahaan mewujudkan keuntungan sebelumnya dan menghasilkan laba di masa yang akan datang (Eliana \& Nurhayati, 2020). Pertumbuhan nilai profitabilitas perusahaan yang tinggi menunjukkan kinerja manajerial perusahaan yang baik.

David Wijaya (2017, h.32) menyatakan bahwa rasio solvabilitas atau leverage menggambarkan kemampuan perusahaan dalam mengelola liabilitasnya, meliputi debt to equity ratio, long-term debt to total capital, debt ratio, interest coverage dan net worth growth ratio. Selain rasio solvabilitas, para investor menggunakan likuiditas perusahaan untuk menilai sehat tidaknya suatu perusahaan (Kariimah dan Septiowati, 2019).

Dipilihnya sub-sektor perdagangan eceran yang terdaftar di Bursa Efek Indonesia (BEI) sebagai sampel objek penelitian karena sektor ini memegang salah satu peran penting dalam perekonomian Indonesia. Subsektor perdagangan eceran ini akan berkembang terus karena merupakan kebutuhan primer dalam kehidupan yang selalu berusaha untuk mengikuti serta memenuhi kebutuhan pasar yang berubah-ubah dan melakukan persaingan dalam mengelola perusahaan sebaik-baiknya agar dapat bersaing di pasar untuk memaksimalkan labanya.

Berikut disajikan Laporan likuiditas, solvabilitas, aktivitas dan profitabilitas pada salah satu perusahaan subsektor perdagangan eceran (retail trade) periode 2012-2018. 


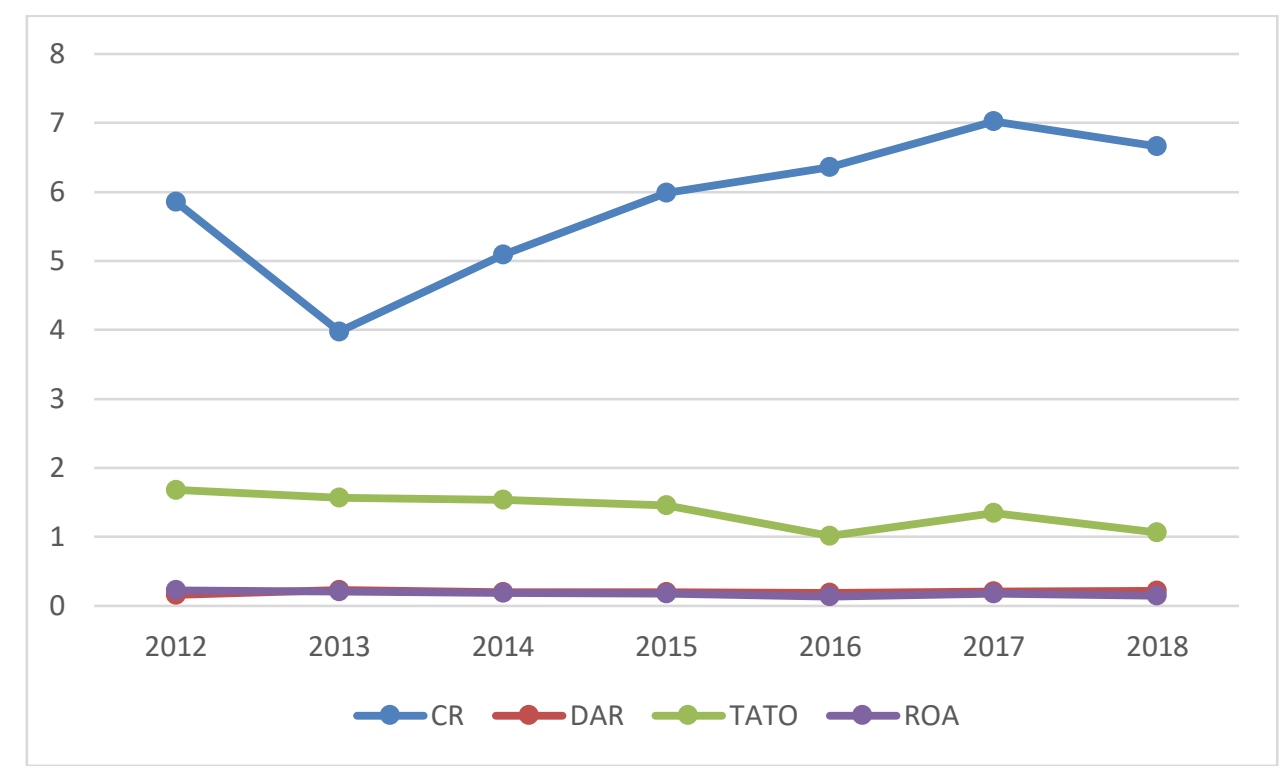

(Sumber : $\underline{w w w . i d x . c o . i d})$

\section{Gambar 1}

Grafik Likuiditas, Solvabilitas, Aktivitas dan Profitabilitas pada PT Ace Hardware Indonesia Tbk.

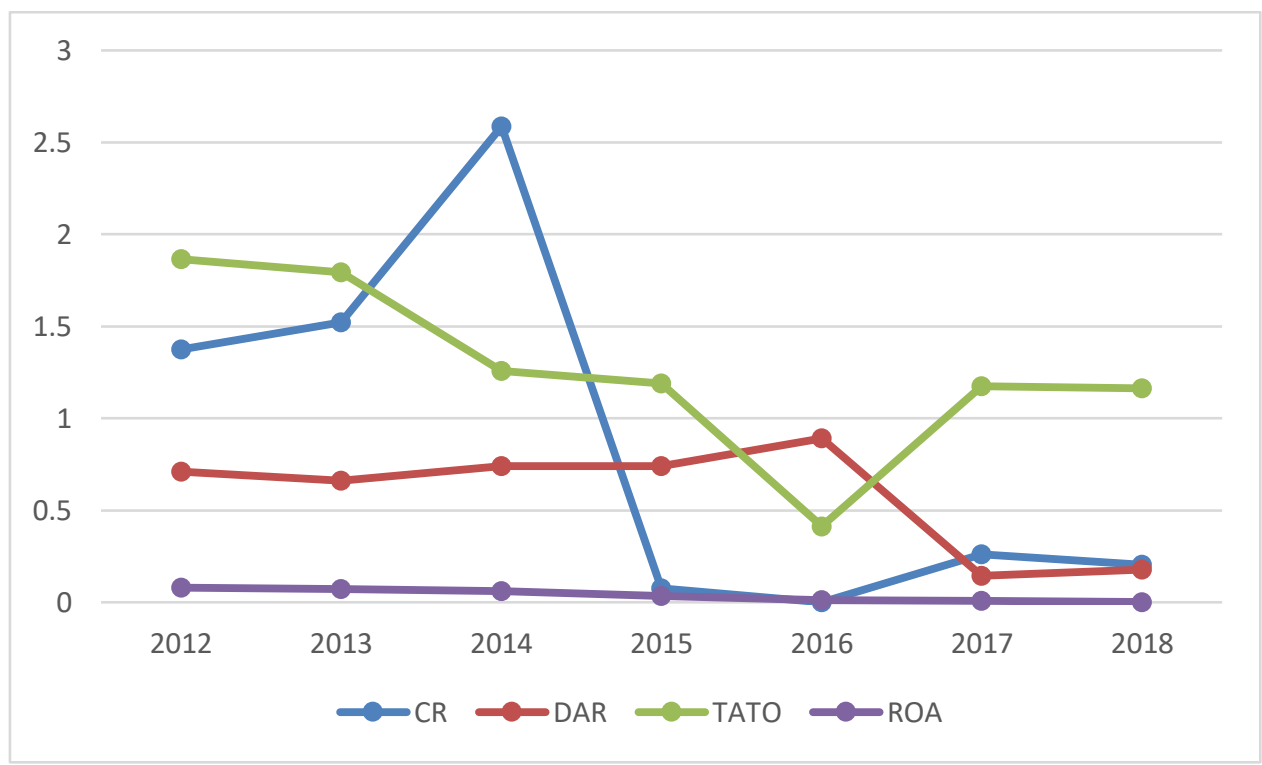

(Sumber : $\underline{\text { www.idx.co.id }})$

\section{Gambar 2}

Grafik Likuiditas, Solvabilitas, Aktivitas dan Profitabilitas pada PT Trikomsel Oke Tbk. 


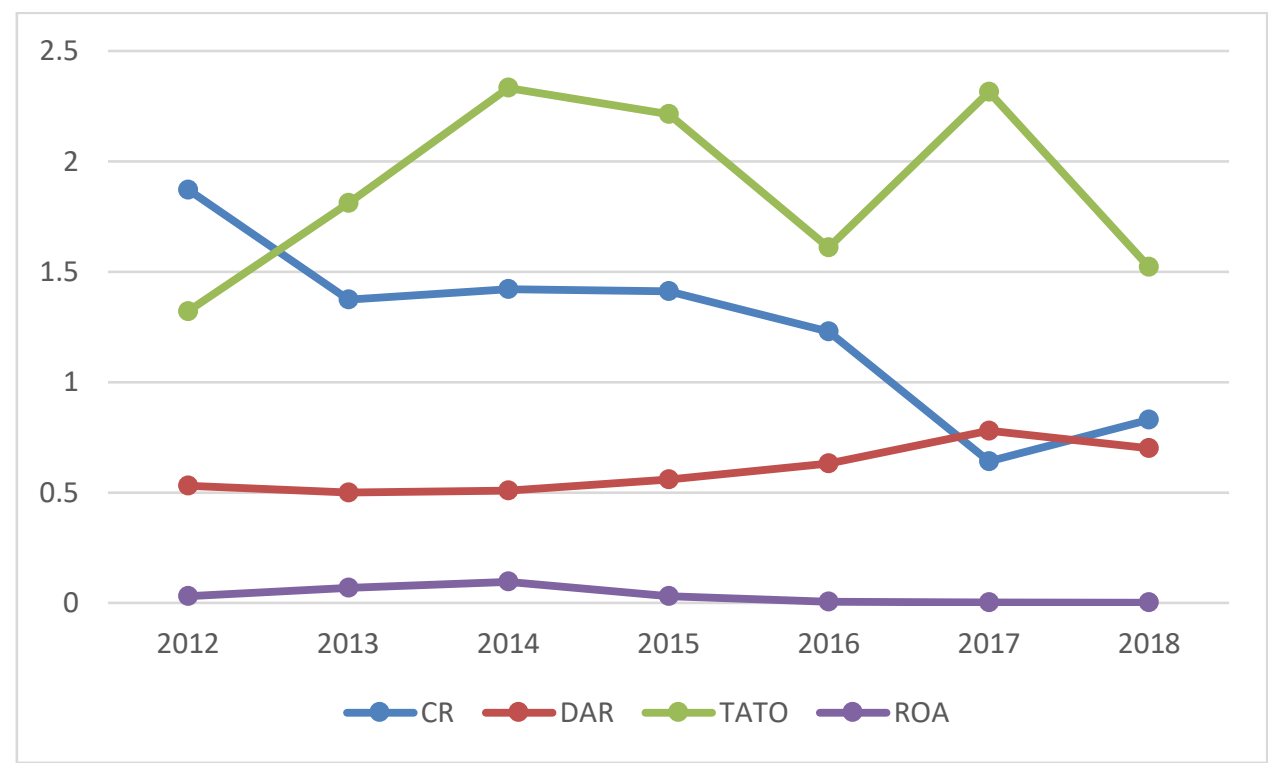

(Sumber : www.idx.co.id)

\section{Gambar 3 \\ Grafik Likuiditas, Solvabilitas, Aktivitas dan Profitabilitas pada PT Matahari Putra Prima Tbk.}

Pendapatan perusahaan dalam periode 2012 sampai 2016 melonjak cukup tinggi dengan kinerja laba bersih yang dapat diatribusikan emiten pedagang eceran kepada entitas induk periode 2015 menurun tajam dan meningkat sedikit di tahun 2017. Dari data pada semua perusahaan yang diteliti, seperti : PT Matahari Departemen Store, Tbk. PT Mitra Adiperkasa, Tbk, PT Midi Utama Indonesia, Tbk dan PT Rimo Catur Lestari, Tbk mengalami kenaikan entitas dari tahun ke tahun. Kemudian pada kondisi kewajiban atau hutang perusahaan dalam periode tahun 2012-2018 dapat dilihat semua perusahaan mengalami peningkatan kewajiban atau hutang setiap tahunnya.

Dapat dilihat perbandingan antara rasio likuiditas, solvabilitas dan aktivitas terhadap profitabilitas perusahaan. Pada kondisi masing-masing rasio, PT Ace Hardware Indonesia Tbk. (ACES), PT Matahari Putra Prima Tbk. (MPPA) dan PT Trikomsel Oke Tbk. (TRIO) memiliki nilai persentase rasio yang menonjol yang mana dapat dilihat dari tahun 2012 ke tahun 2017 DAR mengalami peningkatan, akan tetapi pada ROA perusahaan mengalami penurunan. Dapat dilihat perbandingan antara rasio likuiditas (CR), solvabilitas (DAR), dan rasio aktivitas (TATO) terhadap profitabilitas (ROA) perusahaan. Pada kondisi masing-masing rasio, pada beberapa perusahaan rasio likuiditas mengalami kenaikan dari tahun 2012 sampai tahun 2017. Rasio solvabilitas dan aktivitas berfluktuasi dari tahun 2012 sampai 2018.

Penelitian Amrita Maulidia (2015), menyatakan bahwa ada pengaruh positif dan signifikan secara simultan antara likuiditas, solvabilitas dan aktivitas terhadap profitabilitas. Penelitian Yudi Siswadi (2015), menyatakan bahwa solvabilitas berpengaruh terhadap profitabilitas. Penelitian lain dilakukan oleh Asri Nur W (2018) yang menyebutkan secara parsial, likuiditas dan aktivitas

* Corresponding author's e-mail: dosen02626@unpam.ac.id http://openjournal.unpam.ac.id/index.php/JABI 
berpengaruh positif terhadap profitabilitas. Hasil ini berbanding terbalik dengan penelitian Silviana Sapitri (2017) dan Weny (2018) yang menemukan bahwa Likuiditas tidak berpengaruh signifikan terhadap profitabilitas, tetapi solvabilitas berpengaruh signifikan. Permasalahan dalam penelitian ini adalah untuk mengetahui seberapa besar pengaruh dari masing-masing likuiditas, solvabilitas dan aktivitas terhadap profitabilitas perusahaan

\section{KERANGKA TEORITIS DAN PENGEMBANGAN HIPOTESIS}

Menurut David Wijaya (2017, h.32), analisis rasio keuangan dilakukan dengan cara membandingkan angka tertentu dari satu akun terhadap angka dari akun lainnya. Ada beberapa aspek keuangan yang dianalisis melalui rasio keuangan, antara lain sebagai berikut.

Rasio profitabilitas, yaitu rasio yang menunjukkan kemampuan perusahaan dalam menghasilkan keuntungan (laba), meliputi gross profit margin, basic earning power operating profit margin, net profit margin, return on equity, return on asset, net income (loss) growth ratio dan sales growth ratio.

Rasio likuiditas, yaitu rasio yang mengukur kemampuan perusahaan untuk melunasi liabilitas jangka pendeknya, meliputi current ratio, quick ratio dan cash ratio. Likuiditas yang baik dalam suatu perusahaan mencerminkan perusahaan tersebut memiliki aset lancar yang tersedia untuk memenuhi kewajiban jangka pendek yang akan segera jatuh tempo maupun dalam hal pembayaran dividen (Putri \& Irawati, 2019).

Rasio solvabilitas, yaitu rasio yang menggambarkan kemampuan perusahaan dalam mengelola libilitasnya, meliputi debt to equity ratio, longterm debt to total capital, debt ratio, interest coverage dan net worth growth ratio.

Rasio aktivitas, yaitu rasio yang mengukur efektivitas perusahaan dalam mengelola aset agar menghasilkan penjualan, meliputi receivable turnover, average collection period, inventory turnover, average inventory processing period, payable turn over ratio, payable payment period, cash conversion cycle, total asset turn over, fixed asset turn over, equity turn over, total asset growth ratio, working capital turn over dan working capital to total asset.

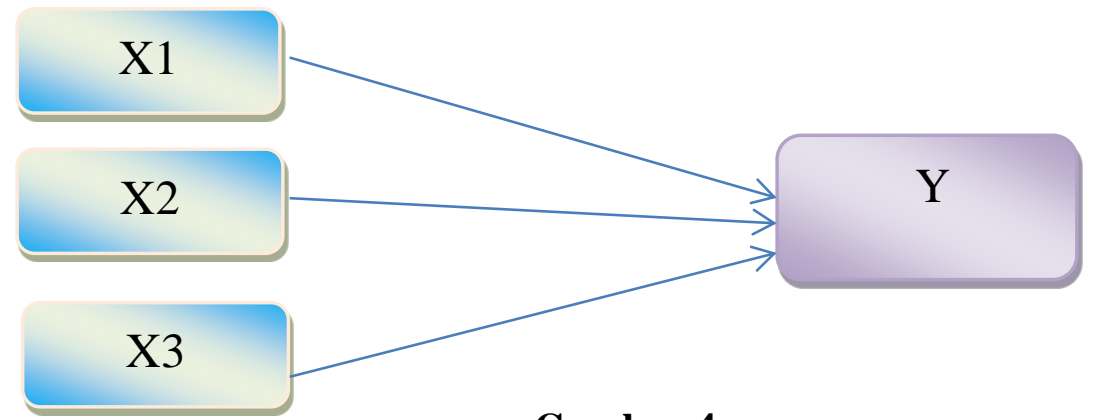

Gambar 4

Kerangka Pemikiran Teoritis

* Corresponding author's e-mail: dosen02626@unpam.ac.id

http://openjournal.unpam.ac.id/index.php/JABI 
Hipotesis 1 (H1): Diduga Likuiditas (Current Ratio) berpengaruh terhadap profitabilitas pada perusahaan subsektor perdagangan eceran (retail trade).

Hipotesis 2 (H2): Diduga Solvabilitas (Debt to Total Asset Ratio) berpengaruh terhadap profitabilitas pada perusahaan subsektor perdagangan eceran (retail trade).

Hipotesis 3(H3): Diduga Aktivitas (Total Assets Turn Over) berpengaruh terhadap profitabilitas pada perusahaan subsektor perdagangan eceran (retail trade).

Hipotesis 4 (H4): Diduga Likuiditas, Solvabilitas dan Aktivitas berpengaruh bersama sama terhadap profitabilitas pada perusahaan subsektor perdagangan eceran (retail trade).

\section{METODE RISET}

Populasi dan sampel penelitian dilakukan pada perusahaan subsektor perdagangan eceran (retail trade) yang terdaftar di Bursa Efek Indonesia. Teknik pengumpulan data yang digunakan adalah teknik dokumentasi dengan mengumpulkan dan menyalin data yang dibutuhkan berupa laporan keuangan dari perusahaan subsektor perdagangan eceran periode 2012-2018 dengan mengakses www.idx.co.id. Operasional Variabel dalam penelitian ini didefinisikan sebagai berikut:

\section{a) Rasio Lancar atau Current Ratio / CR (X1)}

Rasio Likuiditas diproksikan dengan current ratio (CR) sebagai variabel independen. Current Ratio (CR) membandingkan aktiva lancar yang dimiliki perusahaan dengan hutang jangka pendek.

$$
\text { Rumus Current Ratio }=\frac{\text { Aktiva Lancar }}{\text { Kewajiban Lancar }} \quad \mathrm{X} \quad 100 \%
$$

\section{b) Debt to Asset Ratio/ DAR (X2)}

Rasio Solvabilitas diproksikan dengan Debt to Asset Ratio (DAR) sebagai variabel independen. Debt to Asset Ratio (DAR) merupakan rasio utang yang digunakan untuk mengukur perbandingan antara total utang dengan total aktiva.:

$$
\text { Debt to Asset Ratio }=\frac{\text { Total Hutang }}{\text { Total Aktiva }} \times \quad 100 \%
$$

c) Total Asset Turn Over/ TATO (X3) 
Rasio Aktivitas diproksikan dengan Total Asset Turn Over (TATO) sebagai variabel independen. Rasio ini menunjukkan efektivitas penggunaan seluruh harta perusahaan dalam rangka menghasilkan penjualan.

$$
\text { Total Asset Turnover }=\underset{\frac{\text { Benjualan }}{\text { Total Aktiva }}}{\text { X }} \quad 100 \%
$$

d) Profitabilitas (Y)

Profitabilitas sebagai variabel dependen yang diproksikan dengan Return On Assets (ROA) merupakan rasio yang menunjukkan seberapa besar kontribusi aset dalam menciptakan laba bersih.

$$
\text { Return On Assets }=\quad \frac{\text { Laba Bersih }}{\text { Total Aset }}
$$

\section{ANALISIS DATA DAN PEMBAHASAN}

\section{1) Uji Asumsi Klasik}

\section{a. Uji Normalitas}

Pengujian normalitas data dilakukan dengan menggunakan JarqueBera Test. Dalam uji normalitas data dapat dinyatakan berdistribusi normal apabila nilai Probability Jarque-Bera > 0.05, yaitu 0.1063. Dengan demikian data penelitian telah terdistribusi normal, sehingga model regresi data panel telah memenuhi asumsi normalitas data.

b. Uji Multikolinearitas

Uji multikolinearitas dalam penelitian ini dilakukan dengan melihat nilai Variance Inflation Factor (VIF). Data penelitian dapat dikatakan tidak terjadi masalah multikolinearitas apabila nilai Centered VIF $<10$, dapat disimpulkan bahwa tidak terjadi masalah multikolinearitas pada model penelitian ini.

\section{c. Uji Heteroskedastisitas}

Uji heteroskedastisitas pada penelitian ini menggunakan metode Heteroskedasticity Test: Breusch-Pagan-Godfrey. Data penelitian dapat dinyatakan tidak terjadi masalah heteroskedastisitas apabila nilai Probability F-Statistic lebih besar dari 0.05. Dalam penelitian ini, hasil uji Breusch-Pagan-Godfrey dengan nilai Probability F $(3,46)$ adalah $0.0597>0.05$. Sehingga dengan demikian dapat 
disimpulkan data penelitian ini tidak mengalami masalah heteroskedastisitas.

\section{d. Uji Autokorelasi}

Dalam penelitian ini hasil uji Breusch-Godfrey Serial Correlation LM Test dapat dilihat nilai F-statistic Prob. F(2,44) sebesar 0.1810 artinya nilai lebih besar dari 0.05 sehingga dapat disimpulkan bahwa data penelitian tidak terjadi masalah autokorelasi.

Berdasarkan hasil perhitungan uji asumsi klasik yang telah dilakukan, maka dapat disimpulkan bahwa model dalam penelitian ini telah memenuhi syarat uji asumsi klasik dan artinya data penelitian sudah bersifat BLUE (Best, Linear, Unbias, Estimated).

\section{2) Persamaan Regresi Data Panel}

Data panel merupakan gabungan antara jenis data time series dan cross section sehingga data panel merupakan data yang memiliki dimensi waktu dan ruang. Permodelan dalam menggunakan regresi data panel dapat menggunakan tiga pendekatan alternatif metode/model dalam pengolahannya, yaitu Common Effect Model, Fixed Effect Model, dan Random Effect Model.

\section{3) Pemilihan Model Data Panel}

\section{Uji Chow (Common Effect Model vs Fixed Effect Model)}

Uji Chow digunakan untuk memilih model yang tepat dalam data panel, kriteria pengujian yaitu jika nilai probabilitas untuk Crosssection $\mathrm{F}$ lebih besar dari 0.05 maka model yang terpilih adalah common effect model, tetapi jika nilai probabilitas untuk Cross-section $\mathrm{F}$ lebih kecil dari 0.05 maka model yang terpilih adalah fixed effect model.

\section{Tabel 1 Hasil dari Model Common Effect Model}

Dependent Variable: ROA

Method: Panel Least Squares

Date: 08/16/20 Time: $22: 11$

Sample: 20122018

Periods included: 7

Cross-sections included: 10

Total panel (balanced) observations: 70

\begin{tabular}{lrlrr}
\hline \hline \multicolumn{1}{c}{ Variable } & Coefficient & Std. Error & t-Statistic & Prob. \\
\hline \hline C & -0.254993 & 0.080215 & -2.296410 & 0.0293 \\
CR & 0.030131 & 0.010185 & 2.694797 & 0.0028 \\
DAR & 0.134865 & 0.053424 & 2.449952 & 0.0046 \\
TATO & 0.050540 & 0.042420 & 1.608776 & 0.0242 \\
\hline \hline R-squared & 0.022098 & Mean dependent var & 0.091296 \\
Adjusted R-squared & 0.122352 & S.D. dependent var & 0.108118 \\
S.E. of regression & 0.109319 & Akaike info criterion & -1.533641 \\
Sum squared resid & 0.488748 & Schwarz criterion & -1.405155 \\
Log likelihood & 47.67743 & Hannan-Quinn criter. & -1.582605
\end{tabular}

* Corresponding author's e-mail: dosen02626@unpam.ac.id

http://openjournal.unpam.ac.id/index.php/JABI 


\begin{tabular}{llll} 
F-statistic & 3.497147 & Durbin-Watson stat & 0.104161 \\
Prob(F-statistic) & 0.007524 & \\
\hline \hline
\end{tabular}

Sumber: Output Eviews (2020)

Tabel 2

Hasil dari Fixed Effect Model

Dependent Variable: ROA

Method: Panel Least Squares

Date: 08/16/20 Time: 22:15

Sample: 20122018

Periods included: 7

Cross-sections included: 10

Total panel (balanced) observations: 70

\begin{tabular}{crrrr}
\hline \hline \multicolumn{1}{c}{ Variable } & Coefficient & Std. Error & t-Statistic & Prob. \\
\hline C & 0.056609 & 0.044045 & 3.460834 & 0.1435 \\
CR & -0.048059 & 0.020127 & -0.823454 & 0.2478 \\
DAR & -0.070160 & 0.025650 & -2.785971 & 0.0031 \\
TATO & 0.055272 & 0.041235 & 1.414096 & 0.0042 \\
\hline \hline \multicolumn{5}{l}{ Effects Specification } \\
\hline Cross-section fixed (dummy variables) & \\
\hline \hline R-squared & 0.974689 & Mean dependent var & 0.091296 \\
Adjusted R-squared & 0.820939 & S.D. dependent var & 0.108118 \\
S.E. of regression & 0.030400 & Akaike info criterion & -3.982740 \\
Sum squared resid & 0.032678 & Schwarz criterion & -3.565162 \\
Log likelihood & 2.319159 & Hannan-Quinn criter. & -3.816873 \\
F-statistic & 5.973842 & Durbin-Watson stat & 1.579050 \\
Prob(F-statistic) & 0.000000 & & \\
\hline \hline
\end{tabular}

Sumber: Output Eviews (2020)

Tabel 3. Uji Chow

Perusahaan Subsektor Perdagangan Eceran (Retail Trade)

Bursa Efek Indonesia tahun 2012-2018

Redundant Fixed Effects Tests

Equation: Untitled

Test cross-section fixed effects

\begin{tabular}{|c|c|c|c|}
\hline Effects Test & Statistic & d.f. & Prob. \\
\hline Cross-section F & 88.495003 & $(9,57)$ & 0.0000 \\
\hline Cross-section Chi-square & 189.436910 & 9 & 0.0000 \\
\hline
\end{tabular}

$\overline{\text { Sumber: Output E-Views }} \overline{2020}$

Berdasarkan Tabel 3 dapat dilihat probabilitas Cross-section F $(9,57)$ bernilai $0.0000<0.05$ sehingga dapat disimpulkan bahwa fixed effects model lebih tepat dibandingkan dengan common effect model.

* Corresponding author's e-mail: dosen02626@unpam.ac.id

http://openjournal.unpam.ac.id/index.php/JABI 


\section{Uji Hausman (Fixed Effect Model vs Random Effect Model)}

Uji Hausman dengan kriteria penilaian yaitu jika nilai probabilitas Crosssection random lebih besar dari 0.05 maka model yang terpilih adalah random effect model, tetapi jika nilai probabilitas Cross-section random lebih kecil dari 0.05 maka model yang terpilih adalah fixed effect model.

Tabel 4

Hasil dari Fixed Effect Model

Dependent Variable: ROA

Method: Panel Least Squares

Date: 08/16/20 Time: 22:15

Sample: 20122018

Periods included: 7

Cross-sections included: 10

Total panel (balanced) observations: 70

\begin{tabular}{lrlrr}
\hline \hline \multicolumn{1}{c}{ Variable } & Coefficient & Std. Error & t-Statistic & Prob. \\
\hline \hline C & 0.056609 & 0.044045 & 3.460834 & 0.1435 \\
DR & -0.048059 & 0.020127 & -0.823454 & 0.2478 \\
TATO & -0.070160 & 0.025650 & -2.785971 & 0.0031 \\
& 0.055272 & 0.041235 & 1.414096 & 0.0042 \\
\hline \hline \multicolumn{4}{c}{ Effects Specification } & \\
\hline \hline Cross-section fixed (dummy variables) & & \\
\hline \hline & & & \\
R-squared & 0.974689 & Mean dependent var & 0.091296 \\
Adjusted R-squared & 0.820939 & S.D. dependent var & 0.108118 \\
S.E. of regression & 0.030400 & Akaike info criterion & -3.982740 \\
Sum squared resid & 0.032678 & Schwarz criterion & -3.565162 \\
Log likelihood & 2.319159 & Hannan-Quinn criter. & -3.816873 \\
F-statistic & 5.973842 & Durbin-Watson stat & 1.579050 \\
Prob(F-statistic) & 0.000000 & & \\
\hline \hline
\end{tabular}

Sumber: Output Eviews (2020)

Tabel 5. Hasil dari Random Effect Model

Dependent Variable: ROA

Method: Panel EGLS (Cross-section random effects)

Date: 08/16/20 Time: 22:26

Sample: 20122018

Periods included: 7

Cross-sections included: 10

Total panel (balanced) observations: 70

Swamy and Arora estimator of component variances

\begin{tabular}{crrrr}
\hline \hline Variable & Coefficient & Std. Error & \multicolumn{1}{c}{ t-Statistic } & Prob. \\
\hline \hline C & 0.054005 & 0.061327 & 1.048615 & 0.4061 \\
CR & -0.009891 & 0.020035 & -0.992822 & 0.5244 \\
DAR & -0.061826 & 0.047889 & -2.455766 & 0.0021 \\
TATO & 0.057407 & 0.013825 & 4.428992 & 0.0010 \\
\hline \hline
\end{tabular}

* Corresponding author's e-mail: dosen02626@unpam.ac.id http://openjournal.unpam.ac.id/index.php/JABI 


\begin{tabular}{|c|c|c|c|}
\hline \multicolumn{4}{|c|}{ Effects Specification } \\
\hline $\begin{array}{l}\text { Cross-section random } \\
\text { Idiosyncratic random }\end{array}$ & & $\begin{array}{l}0.098710 \\
0.030400\end{array}$ & $\begin{array}{l}0.9472 \\
0.0528\end{array}$ \\
\hline \multicolumn{4}{|c|}{ Weighted Statistics } \\
\hline $\begin{array}{l}\text { R-squared } \\
\text { Adjusted R-squared } \\
\text { S.E. of regression } \\
\text { F-statistic } \\
\text { Prob(F-statistic) }\end{array}$ & $\begin{array}{l}0.169229 \\
0.231466 \\
0.029843 \\
7.481413 \\
0.000343\end{array}$ & $\begin{array}{l}\text { Mean dependent var } \\
\text { S.D. dependent var } \\
\text { Sum squared resid } \\
\text { Durbin-Watson stat }\end{array}$ & $\begin{array}{l}0.018118 \\
0.032022 \\
0.048778 \\
1.106757\end{array}$ \\
\hline \multicolumn{4}{|c|}{ Unweighted Statistics } \\
\hline $\begin{array}{l}\text { R-squared } \\
\text { Sum squared resid }\end{array}$ & $\begin{array}{r}-0.120675 \\
0.823247\end{array}$ & $\begin{array}{l}\text { Mean dependent var } \\
\text { Durbin-Watson stat }\end{array}$ & $\begin{array}{l}0.091296 \\
0.079020\end{array}$ \\
\hline
\end{tabular}

Sumber: Output Eviews (2020)

Berikut disajikan hasil uji Hausman pada penelitian ini.

Tabel 6

Uji Hausman

Perusahaan Subsektor Perdagangan Eceran (Retail Trade)

Bursa Efek Indonesia tahun 2012-2018

Correlated Random Effects - Hausman Test

Equation: Untitled

Test cross-section random effects

\begin{tabular}{lrrr}
\hline \hline Test Summary & $\begin{array}{l}\text { Chi-Sq. } \\
\text { Statistic }\end{array}$ & Chi-Sq. d.f. & Prob. \\
\hline \hline Cross-section random & 11.600332 & 3 & 0.0264 \\
\hline \hline
\end{tabular}

Cross-section random effects test comparisons:

\begin{tabular}{crrrr} 
Variable & Fixed & Random & Var(Diff.) & Prob. \\
\hline \hline CR & -0.010048 & -0.005145 & 0.000000 & 0.2793 \\
DAR & -0.060599 & -0.079891 & 0.000004 & 0.0619 \\
TATO & 0.051609 & 0.057407 & 0.000016 & 0.8275 \\
\hline \hline
\end{tabular}

Sumber: Output Eviews (2020)

Berdasarkan Tabel 6 dapat dilihat probabilitas Cross-section random bernilai $0.0264<0.05$ sehingga dapat disimpulkan bahwa fixed effects model lebih tepat dibandingkan dengan random effect model. Berikut disajikan hasil pemilihan model data panel yang dilakukan pada penelitian ini. 
Tabel 7

Hasil Pemilihan Model

\begin{tabular}{|c|l|c|}
\hline \multicolumn{1}{|c|}{ Pengujian } & \multicolumn{1}{|c|}{ Model yang diperbandingkan } & \multicolumn{1}{c|}{ Hasil Pengujian } \\
\hline Uji Chow & $\begin{array}{l}\text { Common Effect Model vs Fixed } \\
\text { Effect Model }\end{array}$ & Fixed Effect Model \\
\hline Uji Hausman & $\begin{array}{l}\text { Fixed Effect Model vs Random Effect } \\
\text { Model }\end{array}$ & Fixed Effect Model \\
\hline
\end{tabular}

Sumber: Data diolah (2020)

Tabel 7 menunjukkan rangkuman hasil pemilihan model yang telah dilakukan dalam penelitian ini. Berdasarkan tabel tersebut, dapat disimpulkan bahwa model yang paling tepat digunakan dalam penelitian ini adalah fixed effect model.

\section{4) Pengujian Hipotesis}

\section{Pengujian Hipotesis dengan Fixed Effect Model}

Dependent Variable: ROA

Method: Panel Least Squares

Date: 08/16/20 Time: $22: 15$

Sample: 20122018

Periods included: 7

Cross-sections included: 10

Total panel (balanced) observations: 70

\begin{tabular}{crlrr}
\hline \hline \multicolumn{1}{c}{ Variable } & Coefficient & Std. Error & t-Statistic & Prob. \\
\hline C & 0.056609 & 0.044045 & 3.460834 & 0.1435 \\
CR & -0.048059 & 0.020127 & -0.823454 & 0.2478 \\
DAR & -0.070160 & 0.025650 & -2.785971 & 0.0031 \\
TATO & 0.055272 & 0.041235 & 1.414096 & 0.0042 \\
\hline \hline \multicolumn{4}{c}{ Effects Specification } & \\
\hline \hline Cross-section fixed (dummy variables) & & \\
\hline \hline R-squared & 0.974689 & Mean dependent var & 0.091296 \\
Adjusted R-squared & 0.820939 & S.D. dependent var & 0.108118 \\
S.E. of regression & 0.030400 & Akaike info criterion & -3.982740 \\
Sum squared resid & 0.032678 & Schwarz criterion & -3.565162 \\
Log likelihood & 2.319159 & Hannan-Quinn criter. & -3.816873 \\
F-statistic & 5.973842 & Durbin-Watson stat & 1.579050 \\
Prob(F-statistic) & 0.000000 & & \\
\hline \hline
\end{tabular}

Sumber: Output Eviews (2020)

Analisis variabel - variabel yang mempengaruhi Return on Asset Persamaan regresi data panel sebagai berikut :

$$
y=0.0566+\left(-0.0480 X_{1}\right)+\left(-0.0701 X_{2}\right)+0.0552 X_{3}
$$




$$
y=0.0566-0.0480 X_{1}-0.0701 X_{2}+0.0552 X_{3}
$$

- $\quad$ Konstanta sebesar 0.0566; artinya jika Current Ratio, Debt to Total Asset Ratio dan Total Asset Turn Over nilainya 0, maka Return on Assets nilainya sebesar 0.0566 .

- Koefisien variabel Current Ratio ( $\left.\mathrm{X}_{1}\right)$ sebesar -0.0480; artinya setiap peningkatan Current Ratio sebesar 100\%, maka akan menurunkan Return On Assets sebesar 4.8\%, dengan asumsi variabel independen lain nilainya tetap.

- Koefisien variabel Debt to Total Asset Ratio $\left(\mathrm{X}_{2}\right)$ sebesar -0.0701; artinya setiap peningkatan Debt to Total Asset Ratio sebesar 100\%, maka akan menurunkan Return On Assets sebesar 7.01\%, dengan asumsi variabel independen lain nilainya tetap.

- Koefisien variabel Total Asset Turn Over ( $\left.\mathrm{X}_{3}\right)$ sebesar 0.0552; artinya setiap peningkatan Total Asset Turn Over sebesar 100\%, maka akan meningkatkan nilai Return On Assets sebesar 5.52\%, dengan asumsi variabel independen lain nilainya tetap.

\section{Hasil Pengujian Hipotesis}

\section{Uji Koefisien secara parsial}

Hipotesis 1: Dilihat dari koefisiensi variabel Current Ratio mempunyai nilai negatif. Hal ini menunjukkan hubungan current ratio dan Return on Asset tidak searah. Berdasarkan perhitungan Fixed effect model diketahui t-statistic variabel Current ratio sebesar $0.2478>0.05$, maka dapat disimpulkan bahwa variabel current ratio tidak berpengaruh terhadap Return on Asset pada Perusahaan Subsektor Perdagangan Eceran yang diteliti. Maka hipotesis yang menyatakan terdapat pengaruh antara current ratio dan Return on Asset ditolak (Ho diterima). Hal ini membuktikan bahwa pada perusahaan subsektor perdagangan eceran inventory turnovernya rendah sehingga jumlah persediaan dalam aset lancarnya menumpuk semakin besar jumlahnya, yang mengakibatkan current rationya tinggi tetapi profi-tnya justru tidak terpengaruh. Penelitian ini sejalan dengan penelitian Silviana Sapitri (2017) dan penelitian Weny (2018) yang menemukan bahwa Likuiditas tidak berpengaruh terhadap profitabilitas.

Hipotesis 2: Dilihat dari koefisien variabel Debt to Total Asset Ratio mempunyai nilai negatif artinya hubungan Debt to Total Asset Ratio terhadap Return on Assets adalah tidak searah. Nilai t-statistic variabel Debt to Total Asset Ratio sebesar 0.0013 dari hasil perhitungan fixed effect model, karena nilai $0.0013<0.05$ maka dapat disimpulkan pengujian Hipotesis 2 diterima yaitu terdapat pengaruh antara Debt to Total Asset Ratio terhadap Return on Assets. Perusahaan dengan nilai Debt to Total Asset Ratio yang baik (rendah), dianggap memiliki reputasi yang baik sehingga meningkatkan kepercayaan pelanggan dalam melakukan pembelian produknya. Reputasi yang baik itulah yang membuat pihak

* Corresponding author's e-mail: dosen02626@unpam.ac.id

http://openjournal.unpam.ac.id/index.php/JABI 
supplier akan memberikan syarat-syarat pembayaran yang lebih baik sehingga dapat menurunkan harga pokok penjualan dan biaya-biaya lainnya. Perusahaan bereputasi baik juga akan memperoleh keringanan persyaratan dari pemberi pinjaman. Hal ini semua yang menyebabkan profit meningkat. Penelitian ini sejalan dengan penelitian Yudi Siswadi (2012) yang menemukan hasil bahwa solvabilitas berpengaruh terhadap profitabilitas.

Hipotesis 3: Dilihat dari koefisien variabel Total Asset Turn Over mempunyai nilai positif. Hal ini menunjukkan bahwa hubungan antara Total Asset Turn Over terhadap Return on Assets adalah searah. Berdasarkan perhitungan fixed effect model dapat diketahui bahwa nilai probability (t-statistic) variabel Total Assets Turn Over sebesar $0.0042<0.05$ maka dapat disimpulkan pengujian Hipotesis 3 diterima yaitu Total Assets Turn Over secara parsial berpengaruh terhadap Return on Asset terhadap variabel Return on Assets pada Perusahaan Subsektor Perdagangan Eceran yang diteliti. Hal ini membuktikan bahwa semakin tinggi nilai Total Asset Turn Over maka semakin baik juga perusahaan dalam memanfaatkan aset dalam menghasilkan pendapatannya. Sebaliknya pada saat nilai Total Assets Turn Over rendah maka perusahaan tidak memiliki aset dalam menghasilkan pendapatan usaha. Hasil penelitian ini sejalan dengan hasil penelitian yang dilakukan oleh Herman Supardi, H. Suratno, Suyanto (2016) dan penelitian dari Dirvi Surya Abbas (2019) yang menemukan bahwa rasio aktivitas berpengaruh terhadap profitabilitas.

\section{Uji Koefisien secara Simultan}

Nilai Probability (F-statistic) menunjukkan nilai $<0.05$ yaitu sebesar $0.0000<$ 0.05. Artinya variabel Current Ratio, Debt Assets Ratio, dan Total Asset Turn Over berpengaruh secara simultan terhadap variabel Return on Assets.

\section{Analisis Koefisien Determinasi}

Nilai koefisien determintasi (R-squared) menunjukkan nilai sebesar 0.9746 atau sebesar $97.46 \%$. Artinya perubahan variabel Return on Assets karena kontribusi variabel Current Ratio, Debt Assets Ratio, dan Total Assets Turn Over sebesar 97.46\%. Sedangkan sisanya sebesar 2.54\% (100 - 97.46) dipengaruhi oleh variabel lain yang tidak dimasukkan dalam model penelitian ini.

\section{KESIMPULAN \& SARAN}

\section{Kesimpulan}

1) Current Ratio secara parsial tidak berpengaruh terhadap Return on Assets pada perusahaan subsektor perdagangan eceran yang terdaftar pada BEI. Angka Current Ratio yang tinggi belum menjamin perusahaan memiliki kas cukup dalam memenuhi kebutuhan lancarnya. Dapat juga terjadi penagihan piutang yang macet pada perusahaan. 
2) Debt to Total Asset Ratio secara parsial berpengaruh terhadap Return on Assets pada perusahaan subsektor perdagangan eceran yang terdaftar di BEI. Berdasarkan perhitungan fixed effect model dapat diketahui nilai Debt to Total Asset Ratio pada perusahaan subsektor perdagangan eceran pada penelitian ini menunjukkan penurunan dengan nilainya yang semakin kecil dari tahun ke tahun.

3) Total Asset Turn Over secara parsial berpengaruh terhadap Return on Assets pada perusahaan subsektor perdagangan eceran yang terdaftar di BEI. Berdasarkan perhitungan Fixed Effect Model dapat disimpulkan bahwa variabel Total Asset Turn Over berpengaruh terhadap variabel Return on Assets.

4) Berdasarkan perhitungan fixed effect model dapat diketahui bahwa variabel Current Ratio, Debt to Total Assets Ratio, dan Total Asset Turn Over secara bersama-sama berpengaruh terhadap variabel Return on Assets. Hal ini menunjukkan bahwa dengan tersedianya kas untuk membayar hutang jatuh tempo, hutang perusahaan yang setiap tahunnya menurun dan penjualan yang meningkat mempengaruhi Return on Assets.

\section{Saran}

Bagi peneliti selanjutnya yang akan meneliti bidang ilmu yang sama sebaiknya tidak terbatas pada perusahaan subsektor perdagangan eceran saja tetapi dapat menambah variabel penelitian seperti Cash Ratio, Biaya Operasional, Receivable Turn Over, Debt to Equity Ratio dan juga memperpanjang periode penelitian, lalu dapat menguji hipotesis kembali.

\section{DAFTAR PUSTAKA}

Abbas, Dirvi Surya dan Pambudy, Januar Eky. (2019). Pengaruh Rasio Aktivitas terhadap Profitabilitas (pada Perusahaan Pertambangan yang Terdaftar di BEI Periode 2010-2018)

Eliana, Nurhayati dan Ayumiati. (2020). Pengaruh Ukuran Perusahaan, Leverage dan Profitabilitas Terhadap Penerapan Good Corporate Governance Bisnis Syariah Bus di Indonesia. Jurnal Akuntansi Berkelanjutan Indonesia 3(2), 182-192.

Indrayani, Lioni. (2018). Pengaruh Likuiditas, Solvabilitas dan Aktivitas Terhadap Profitabilitas pada Perusahaan Subsektor Perdagangan Eceran (Terdaftar di Bursa Efek Indonesia Periode 2012-2016. Universitas Pakuan. Bogor.

Irham Fahmi. (2014). Manajemen Keuangan Perusahaan dan Pasar Modal. Jakarta: Penerbit Mitra Wacana Media.

* Corresponding author's e-mail: dosen02626@unpam.ac.id

http://openjournal.unpam.ac.id/index.php/JABI 
Jurnal Akuntansi Berkelanjutan Indonesia - Vol. 3, No. 3, Sep 2020 - Indrayani

Kariimah, Maratun \& Septiowati, R. (2019). Pengaruh Manajemen Laba dan Rasio Likuiditas Terhadap Agresivitas Pajak. Jurnal Akuntansi Berkelanjutan Indonesia 2(1), 17-37

Kasmir. (2010). Analisa Laporan Keuangan. Rajawali, Jakarta

Putri, N. R., \& Irawati, W. (2019). Pengaruh Kepemilikan Manajerial dan Effective Tax Rate terhadap Kebijakan Dividen dengan Likuiditas sebagai Variabel Moderating. Jurnal Kajian Akuntansi, 3(1), 93-108.

Sapitri, Silviana. (2017). Pengaruh Likuiditas terhadap Kebijakan Deviden dengan Profitabilitas sebagai Variabel Intervening. Jurnal Riset Akuntansi Terpadu Vol. 10,No.2, 270-279.

Siallagan, Hamonagan \& Mas'ud Machfoedz. (2006). Mekanisme Corporate Governance, Kualitas Laba dan Nilai Perusahaan. Simposium Nasional Akuntansi IX, Padang, 23-26 Agustus

Siswadi, Yudi. (2012). Pengaruh Efisiensi Modal Kerja, Likuiditas dan Solvabilitas terhadap Profitabilitas. Jurnal Riset Akuntansi dan Bisnis.Vol.12,No.1.

Sugiyono. (2014). Metode Penelitian Kuantitatif, Kualitatif dan R\&D. Jakarta: Alfabeta

Syafri Harahap, Sofyan. (2011). Analisis Kritis atas Laporan Keuangan. Jakarta: Rajawali Pers.

Wahyuni, Asri Nur. (2018). Analisis Likuiditas, Solvabilitas dan Aktivitas Perusahaan terhadap Profitabilitas pada Perusahaan Manufaktur. Jurnal Manajemen Vol 15. No. 1, 1-17.

Wiagustini, Ni luh Putu. (2010). Dasar-Dasar Manajemen Keuangan. Denpasar. Udayana University Press.

Wijaya, David. (2017). Manajemen Keuangan Konsep dan Penerapannya. Jakarta. Grasindo. 